Full Length Article

\title{
Multifunctional EuYVO 4 nanoparticles coated with mesoporous silica
}

\author{
Larissa G. Justino ${ }^{a}$, Karina Nigoghossian ${ }^{\text {b }}$, Ticiana S.O. Capote ${ }^{c}$, \\ Raquel M. Scarel-Caminaga ${ }^{c}$, Sidney J.L. Ribeiro ${ }^{\mathrm{b}}$, José Maurício A. Caiut ${ }^{\mathrm{a}, *}$ \\ a Departamento de Química, Faculdade de Filosofia, Ciências e Letras de Ribeirão Preto, Universidade de São Paulo, 14040-901 Ribeirão Preto, SP, Brazil \\ ${ }^{\mathrm{b}}$ Inst. of Chemistry - São Paulo State University- UNESP, 14801-970 Araraquara, SP, Brazil \\ ${ }^{\mathrm{c}}$ Department of Morphology, Dental School at Araraquara, Univ. Estadual Paulista - UNESP, Araraquara, SP, Brazil
}

\section{A R T I C L E I N F O}

\section{Article history:}

Received 16 March 2016

Received in revised form

15 June 2016

Accepted 4 July 2016

Available online 7 July 2016

Keywords:

Rare earth

Surface modification

Luminescence

\begin{abstract}
A B S T R A C T
Mesoporous structures are interesting materials for the incorporation of dyes, drugs, and luminescent systems, leading to materials with important multifunctionalities. In a very unique way, these guest/host materials combine the high stability of inorganic systems, new guest-structuring features, and adsorption mechanisms in their well-defined pores. This work evaluates the luminescent properties of rare earth-doped $\mathrm{YVO}_{4}$ nanoparticles coated with a mesoporous silica shell. The use of two different synthesis methodologies allowed for particle size control. The crystalline phase emerged without further heat treatment. The mesoporous shell decreased undesirable quenching effects on $\mathrm{YVO}_{4}: \mathrm{Eu}^{3+}$ nanoparticles and rendered them biocompatible. The materials prepared herein could have interesting applications as luminescent markers or drug release systems.
\end{abstract}

(c) 2016 Elsevier B.V. All rights reserved.

\section{Introduction}

Rare earth-based materials displaying narrowband emission bands and relatively long excited state lifetimes have attracted much attention-they can be used to produce versatile photoluminescent devices with applications in lasers [1], scintillators [2], OLEDs [3], UVC phosphors [4], optical amplifiers [5], and nanothermometers [6], just to mention a few examples. Their luminescent properties are consequence of the well shielded $4 \mathrm{f}^{n}$ electrons from its environment by the closed $5 s^{2}$ and $5 p^{6}$ shells. The limited interaction of their $4 \mathrm{f}^{n}$ electrons with the surrounding medium gives rise to an array of luminescence properties depending on the matrix in which the rare earth ion is located. For instance, europium emissions broaden non-homogeneously when these ions are doped into the highly porous $\gamma-\mathrm{Al}_{2} \mathrm{O}_{3}$ [7], but europium emissions are narrow in the case of $\mathrm{Y}_{3} \mathrm{Al}_{5} \mathrm{O}_{12}: \mathrm{Eu}^{3+}$ (YAG) [8]. Inorganic nanoparticles with enhanced luminescence properties have diverse uses; e.g., they can be components of photonic devices or act as biological labels. $\mathrm{Eu}^{3+}$-doped $\mathrm{YVO}_{4}$ nanoparticles are a remarkable candidate for new applications because their structure allows high solubilization of the rare earth ions [9]. Indeed, as a result of their high luminescence efficiency, $\mathrm{Eu}^{3+}$-doped $\mathrm{YVO}_{4}$ nanoparticles have been considered an important red phosphor since 1964. In addition,

\footnotetext{
* Corresponding author. Tel.: +55 1633154444 .

E-mail address: caiut@ffclrp.usp.br (J.M.A. Caiut).
}

these nanoparticles can be prepared at relatively low temperatures [10]. $\mathrm{Eu}^{3+}$-doped $\mathrm{YVO}_{4}$ nanoparticles provide a chemically and mechanically stable vehicle that protects the encapsulated active rare earth ions from external perturbations. This may lead to important biological applications, namely the use of these nanoparticles as imaging agents and diagnostic probes. Nevertheless, these nanoparticles display significant toxicity [11], which requires further surface modification for introduction of active molecules (as in the case of drug delivery system) or to ensure that the nanoparticles are safe and biocompatible. Mesoporous structures (with large pore volume and surface area) are very interesting hosts for the incorporation of dyes, drugs, and luminescent systems, leading to materials with important multifunctionalities [12]. In a very interesting way, these guest/host materials combine the high stability of inorganic systems, new guest-structuring features, and adsorption mechanisms in their well-defined pores. Herein, we report the synthesis of a new heteronanostructure consisting of $\mathrm{YVO}_{4}: \mathrm{Eu}^{3+}$ nanoparticles coated with a mesoporous silica shell. The vanadate particles were obtained by two different methodologies, which allowed for particle size control. The mesoporous silica coating played an important role in the luminescence properties as well as in the toxicity behavior of the $\mathrm{YVO}_{4}: \mathrm{Eu}^{3+}$ particles. The results from this work allow creating a simple luminescent label or a multifunctional drug delivery system through incorporation of biological active molecules, such as NO, for sustained release or photodynamic therapy (PDT). 


\section{Material and methods}

\subsection{Synthesis of $\mathrm{YVO}_{4}: \mathrm{Eu}^{3+}$ nanoparticles}

\subsubsection{Synthesis of $\mathrm{YVO}_{4}: \mathrm{Eu}^{3+}$ by the colloidal method}

$\mathrm{Y}\left(\mathrm{NO}_{3}\right)_{3}$ and $\mathrm{Eu}\left(\mathrm{NO}_{3}\right)_{3}$ solutions (both at $0.1 \mathrm{~mol} \mathrm{~L}^{-1}$ ) were prepared by dissolving the respective oxides in nitric acid. To an aqueous solution of $\mathrm{Y}_{0.9} \mathrm{Eu}_{0.1} \mathrm{NO}_{3}\left(0.1 \mathrm{~mol} \mathrm{~L}^{-1}\right), 7.5 \mathrm{~mL}$ of sodium citrate $(0.75 \mathrm{mmol})$ was added under stirring. The resulting white precipitate consisting of lanthanide citrate was reacted with $10 \mathrm{~mL}$ of $\mathrm{Na}_{3} \mathrm{VO}_{4}$ solution ( $1 \mathrm{mmol}$ ), which resulted in a colorless mixture that was heated at $60{ }^{\circ} \mathrm{C}$ for $1 \mathrm{~h}$. The obtained nanoparticles suspension was dialyzed against water and lyophilized, to give white $\mathrm{YVO}_{4}: \mathrm{Eu}^{3+}$ powders [10].

\subsubsection{Synthesis of $\mathrm{YVO}_{4}: \mathrm{Eu}^{3+}$ by reverse microemulsion}

A reverse emulsion was obtained by mixing $60 \mathrm{~mL}$ of cyclohexane, $7 \mathrm{~mL}$ of 1 -octanol, and $7 \mathrm{~mL}$ of triton X-45 (octylphenol ethoxylate surfactant), under stirring. Synthesis of the nanoparticles was carried out by adding the following aqueous solutions dropwise: $3.6 \mathrm{~mL}$ of $\mathrm{Y}\left(\mathrm{NO}_{3}\right)_{3}(0.36 \mathrm{mmol}), 0.4 \mathrm{~mL}$ of $\mathrm{Eu}\left(\mathrm{NO}_{3}\right)_{3}$ $(0.04 \mathrm{mmol})$, and, after $30 \mathrm{~min}, 4 \mathrm{~mL}$ of $\mathrm{Na}_{3} \mathrm{VO}_{4} 0.1 \mathrm{~mol} \mathrm{~L}^{-1}$ $(0.4 \mathrm{mmol})$. The reaction was kept under stirring for $24 \mathrm{~h}$, and the emulsion was broken by addition of $75 \mathrm{~mL}$ of acetone. Finally, the nanoparticles suspension was centrifuged, washed with water and ethanol (three times each solvent), and dried under low pressure.

\subsection{Mesoporous coating}

$\mathrm{YVO}_{4}: \mathrm{Eu}^{3+}(5 \mathrm{mg})$ was dispersed in $5.6 \mu \mathrm{L}$ of oleic acid, which was followed by addition of $2 \mathrm{~mL}$ of chloroform, under stirring [13]. The mixture was sonicated in an ultrasonic bath for 2 min. After that and still under stirring, a cetyltrimethyl ammonium bromide aqueous solution (CTAB, $10 \mathrm{mg}$ in $5 \mathrm{~mL}$ of water) was added, and the reaction was kept under heating at $60^{\circ} \mathrm{C}$ for $1 \mathrm{~h}$, which caused chloroform to evaporate completely. Then, $30 \mathrm{~mL}$ of water, $0.3 \mathrm{~mL}$ of ammonium hydroxide, $0.25 \mathrm{~mL}$ of tetraethylorthosilicate (TEOS), and $2.5 \mathrm{~mL}$ of ethyl acetate were added under constant stirring, which continued for $30 \mathrm{~min}$. The resulting suspension was centrifuged, and the resulting nanoparticles were washed with water and ethanol (three times each solvent) and dried under low pressure. Finally, only for the cytotoxicity studies, the mesoporous particles were heat-treated at $800{ }^{\circ} \mathrm{C}$ for $5 \mathrm{~h}$ at a heating rate of $1{ }^{\circ} \mathrm{C} / \mathrm{min}$, to cross off the surfactant from pores.

\subsection{Cell culture experiments}

Chinese hamster ovary cells (CHO-K1) were cultured in 1:1 Ham-F10+D-MEM medium (Sigma ${ }^{\circledR}$, St. Louis, MO) supplemented with $10 \%$ fetal bovine serum (FBS) (Cultilab, Campinas, Brazil) and antibiotics $\left[0.06 \mathrm{gL}^{-1}\right.$ penicillin (Sigma $\left.{ }^{\circledR}\right), 0.10 \mathrm{gL}^{-1}$ streptomycin (Sigma ${ }^{\circledR}$ ), 1\% kanamycin (Gibco, Carlsbad, CA), and $1 \%$ ciprofloxacin (Hifloxan ${ }^{\circledR}$, Halexistar)] in $25-\mathrm{cm}^{2}$ culture flasks at $37{ }^{\circ} \mathrm{C}, 5 \% \mathrm{CO}_{2}$. The cells were used between the third and eighth passages.

Eluates of the materials $\mathrm{YVO}_{4}: \mathrm{Eu}^{3+}$ (colloidal method) and $\mathrm{YVO}_{4}: \mathrm{Eu}^{3+}$ with porous $\mathrm{SiO}_{2}$ coating (colloidal method) obtained before and after heat treatment (samples NTT-YVO ${ }_{4} \mathrm{Si}$ and TT$\mathrm{YVO}_{4} \mathrm{Si}$, respectively) were obtained according to ISO 10993-12, by considering the surface area $\left(6 \mathrm{~cm}^{2} / \mathrm{mL}\right)$. The materials were immersed in 1:1 Ham-F10+D-MEM medium (Sigma ${ }^{\circledR}$, St. Louis, MO) without fetal bovine serum (FBS) at $37{ }^{\circ} \mathrm{C}$ for $24 \mathrm{~h}$ and shaken in an incubator at $133 \mathrm{rpm}$ (New Brunswick Scientific-Excella E24 Incubator Shaker Series).

\subsection{Cytotoxicity test-XTT assay}

Cytotoxicity of the prepared materials was assessed by the XTT assay. The Cell Proliferation Kit II was used to determine cell viability.

After seeding for $24 \mathrm{~h}, \mathrm{CHO}-\mathrm{K} 1$ cells $\left(2 \times 10^{4}\right.$ cells seeded) were treated with the eluates of the materials $\mathrm{YVO}_{4}, \mathrm{NTT}-\mathrm{YVO}_{4} \mathrm{Si}$, and $\mathrm{TT} \mathrm{YVO}_{4} \mathrm{Si}$ for $24 \mathrm{~h}$ in 24 -well plates. Each well containing eluate $(1 \mathrm{~mL})$ was supplemented with $10 \%$ FBS. Negative controls (NC) consisted of wells containing culture medium supplemented with $10 \%$ FBS in the absence of any eluate (untreated controls). Positive controls (PC) were CHO-K1 cells treated with doxorubicin ( $3 \mu \mathrm{g} \mathrm{mL} \mathrm{m}^{-1}$, the sufficient amount to inhibit cell growth) for $24 \mathrm{~h}$. All the treatments were carried out in duplicate. After treatment, the cultures were washed with PBS solution, and fresh medium was added. After $24 \mathrm{~h}$ of incubation, the cultures were washed with PBS solution, and $500 \mu \mathrm{L}$ of DMEM without phenol red was added, which was followed by addition of $60 \mu \mathrm{L}$ of the XTT/electron solution (50:1) (Cell Proliferation Kit II - Roche Applied Science). After $3 \mathrm{~h}$ of reaction, the supernatant was transferred to a 96 -well culture plate, and the absorbance at 492 and $690 \mathrm{~nm}$ was measured with a Microplate Reader (VersaMax, Molecular Devices, Sunnyvale, CA). The absorbance is directly proportional to the number of viable cells in each treatment after $24 \mathrm{~h}$ of exposure. Three independent experiments were conducted.

\subsection{Statistical analysis}

The experimental results are expressed as the mean and standard error. The Shapiro-Wilk test was used to assess the normality of the data, and Levene's test was employed to test homogeneity. In view of the results, parametric tests were applied. One-way analysis of variance (ANOVA) followed by Tukey's test was used. The data were also analyzed by Dunnett's test to compare each sample to the NC. GraphPad Prism 6.0c was used to perform the tests. Differences were considered statistically significant when $p<0.05$.

\subsection{Characterization}

Powders were characterized by X-ray diffraction (XRD) at room temperature conducted on a Rigaku Geigerflex $D /$ max-c diffractometer with monochromatic $\mathrm{CuK} \alpha$ radiation $(\lambda=1.5406 \AA)$. The hydrodynamic size distributions of the samples were determined by dynamic laser light scattering (DLS) with a Malvern Instruments ZETASIZER 3000, model DTS5300. The powders were observed by transmission electron microscopy (TEM) under a Philips-CM120 microscope, by scanning electron microscopy (SEM) under a ZEISS EVO 50 microscope, and by EDS (energydispersive X-ray spectroscopy - IXRF Systems 500 Digital processing). Fourier transform infrared (FT-IR) spectra were recorded in $\mathrm{KBr}$ pellets by using an IRPrestige-21 (Shimadzu) spectrometer. Luminescence spectra were recorded at room temperature on a Jobin-Yvon model Fluorolog FL3-22 spectrometer equipped with an R928 Hammamatsu photomultiplier and a $450 \mathrm{~W}$ Xe excitation lamp. The excitation spectra were corrected with respect to the Xe lamp intensity and the spectrometer (excitation monochomator) response, and the emission spectra were corrected for the spectrometer (emission monochromator) response. Emission decay measurements were accomplished on the same equipment by using a pulsed Xe $(3 \mu \mathrm{s})$ bandwidth source.

\section{Results and discussions}

Fig. 1 shows the powder X-ray diffraction (XRD) patterns of the as-prepared $\mathrm{YVO}_{4}$ :Eu nanophosphors. Both methodologies produced 
powders with a series of Bragg reflections perfectly indexed as tetragonal $\mathrm{YVO}_{4}$ (JCPDS 17-0341, $a=0.7119 \mathrm{~nm}, c=0.6289 \mathrm{~nm}$ ), with peaks labeled (200), (112), (202), (312) at $2 \theta=25,33,39$, and $50^{\circ}$, respectively $[14,15]$. This structure consists of chains of alternating edge-sharing $\mathrm{VO}_{4}$ tetrahedra and $\mathrm{YO}_{8}$ bisdisphenoid extending parallel to the crystal $c$ axis and joined laterally by edge-sharing bisdisphenoids. The broad peaks corresponded to a sample consisting of nanocrystals. In addition, the larger particles obtained by reverse microemulsion synthesis afforded $\mathrm{YVO}_{4}$ :Eu nanophosphors with higher crystallinity in the final powder. Heat treatment can provide larger crystal phosphors; e.g., Huignard et al. [16] obtained microcrystals after thermal treatment of the material at $1000^{\circ} \mathrm{C}$.

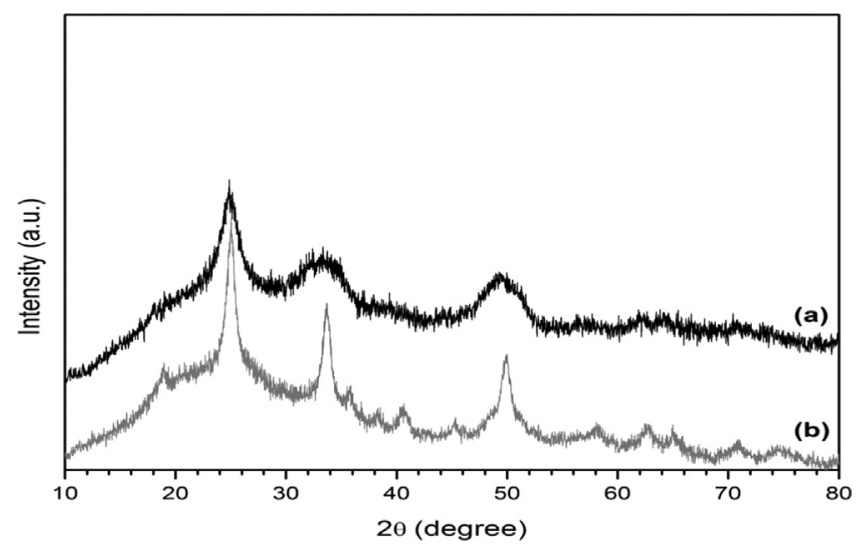

Fig. 1. Powder X-ray diffraction pattern of $\mathrm{YVO}_{4}: \mathrm{Eu}^{3+}$ samples obtained by (a) the colloidal method and by (b) reverse microemulsion synthesis.
The electron microscopy images evidenced differences between the samples obtained by the colloidal and the microemulsion methodologies. The colloidal $\mathrm{YVO}_{4}$ :Eu particles (Fig. 2(a)) presented anisotropic morphology. The nanoparticles were dispersed in citrate, which avoided aggregation and gave rise to particles with a diameter of $15 \mathrm{~nm}$. This value agreed with the value obtained from DLS measurements $(20 \mathrm{~nm})$, which implied that the nanoparticles were well dispersed in solution. In the case of the nanoparticles obtained by reverse microemulsion, the micellar system defined particle size and shape [17], and there was no citrate as steric stabilizer. The average size determined by SEM was below $100 \mathrm{~nm}$ (Fig. 2(c)). Based on DLS measurements, size distribution was larger than the size distribution verified for the colloidal nanoparticles. The hydrodynamic diameter varied from 40 to $70 \mathrm{~nm}$ for the nanoparticles obtained by reverse microemulsion.

Fig. 2(b) and (d) depict the increase in particle size observed after the mesoporous coating processes. The average size of the mesoporous coating measured for colloidal $\mathrm{YVO}_{4}$ : Eu was $50 \mathrm{~nm}$, with narrow size distribution. In contrast, as a consequence of the initial large size distribution of the $\mathrm{YVO}_{4}: \mathrm{Eu}^{3+}$ obtained by reverse microemulsion, size distribution of this material after mesoporous coating was broader, but the particles retained their spherical shape.

Electrostatic and steric repulsions by citrate ions stabilized the colloidal $\mathrm{YVO}_{4}$ :Eu particles suspension [18]. These ions were replaced with oleic acid in the $\mathrm{YVO}_{4}$ :Eu particles obtained by reverse microemulsion, which enhanced their interaction with CTAB. The hydrophobic tail of the CTAB molecule interacted strongly with the hydrophobic oleate ligand at the $\mathrm{YVO}_{4}$ :Eu particle surface synthesized by reverse microemulsion [19]. Consequently, the double-capped nanoparticles (oleate/CTAB) were stable in the aqueous phase. CTAB directed the structure toward
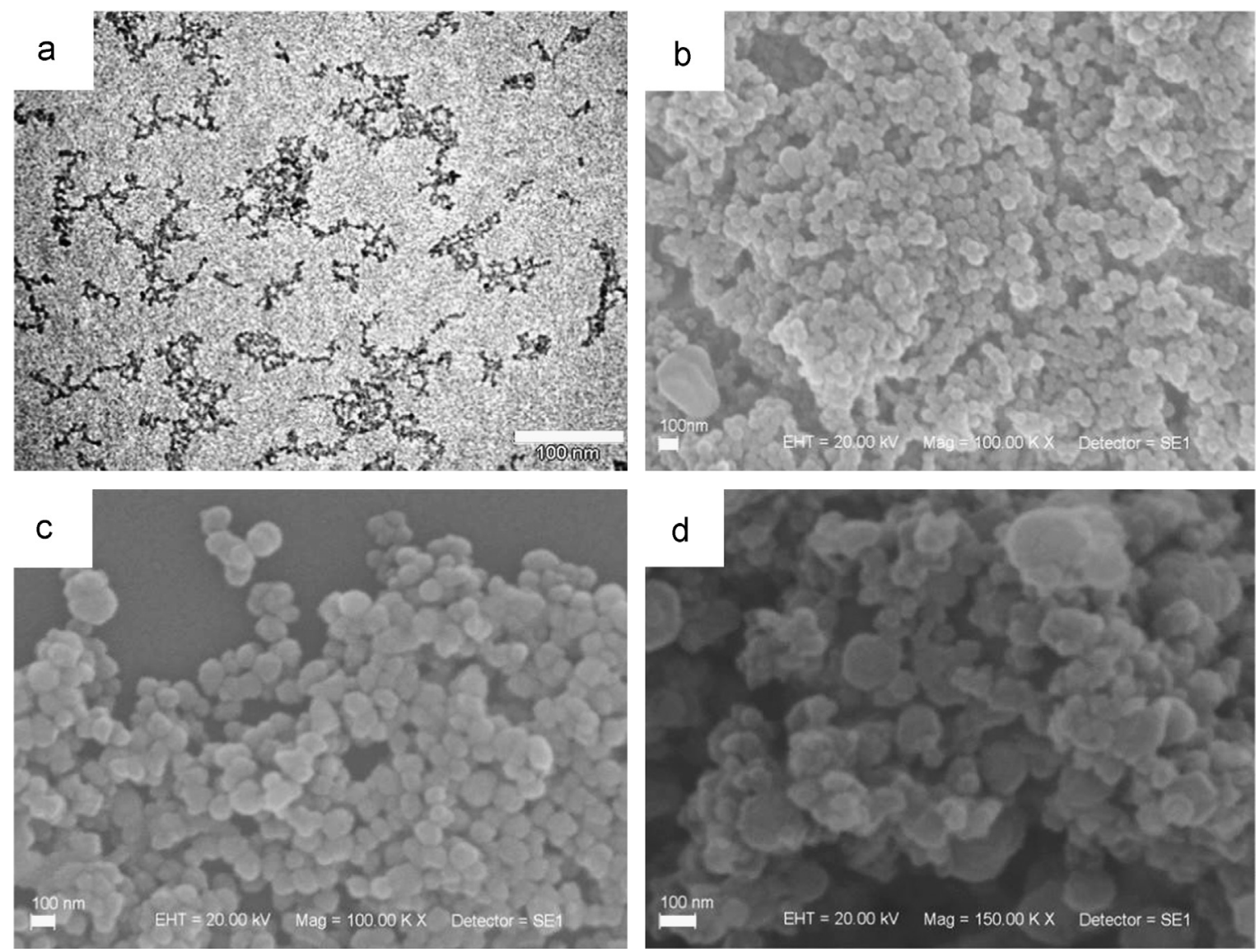

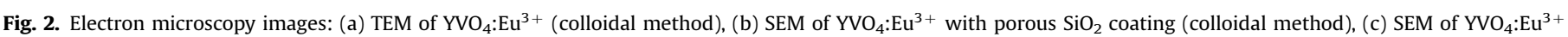
(reverse microemulsion synthesis), and (d) SEM of $\mathrm{YVO}_{4}: \mathrm{Eu}^{3+}$ with porous $\mathrm{SiO}_{2}$ coating (reverse microemulsion synthesis). 

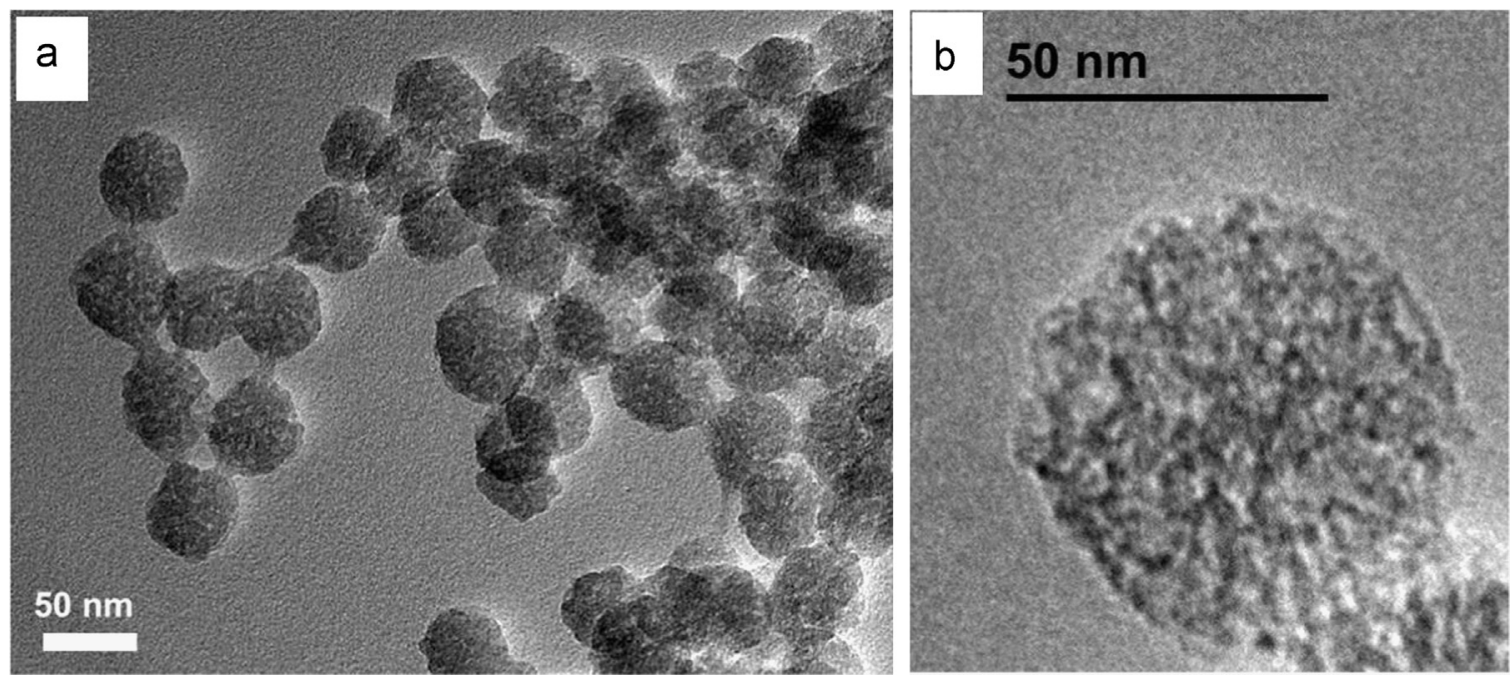

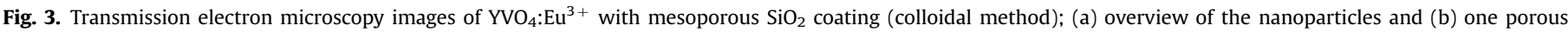
particle.

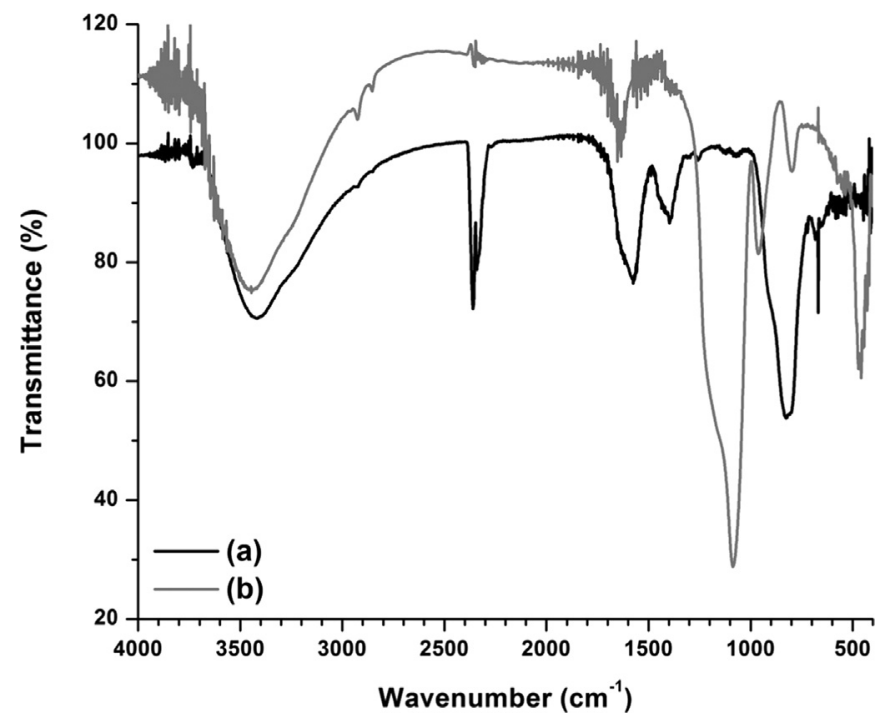

Fig. 4. FTIR spectra of (a) $\mathrm{YVO}_{4}: \mathrm{Eu}^{3+}$ (colloidal method) and (b) $\mathrm{YVO}_{4}: \mathrm{Eu}^{3+}$ with mesoporous $\mathrm{SiO}_{2}$ coating (colloidal method).

formation of the mesoporous silica spheres as well. The critical micelle concentration (CMC) of CTAB is $0.9 \times 10^{-3} \mathrm{~mol} / \mathrm{L}$ in water [20]. In this work, the CTAB concentration was $6.8 \times 10^{-3} \mathrm{~mol} / \mathrm{L}$. Therefore, an ordered micelle phase, packed hexagonally or as lamellae, was expected. However, TEM did not evidence any ordered porous system (Fig. 3). The Ferret diameter measured in the TEM images revealed that the mean pore size was $5 \mathrm{~nm}$.

EDS and FTIR spectroscopies corroborated the chemical composition of the mesoporous coating. A large band at $790 \mathrm{~cm}^{-1}$ dominated the spectrum of $\mathrm{YVO}_{4}: \mathrm{Eu}^{3+}$ (colloidal method, Fig. 4 (a)). This band referred to vibrations of the $\mathrm{V}-\mathrm{O}$ bond [18]. The two bands at 1390 and $1580 \mathrm{~cm}^{-1}$ were due the presence of citrate ligands on the surface of the particles, $\nu_{\mathrm{s}}\left(\mathrm{COO}^{-}\right)$and $\nu_{\mathrm{as}}\left(\mathrm{COO}^{-}\right)$, respectively. After the mesoporous coating process (Fig. 4(b)), the FTIR spectrum displayed bands at $465(\delta(\mathrm{Si}-\mathrm{O}-\mathrm{Si})), 800\left(\nu_{\mathrm{s}}(\mathrm{Si}-\mathrm{O}-\right.$ $\mathrm{Si})), 965(\nu(\mathrm{Si}-\mathrm{OH}))$, and $1085 \mathrm{~cm}^{-1}\left(\nu_{\mathrm{as}}(\mathrm{Si}-\mathrm{O}-\mathrm{Si})\right)$ [21]. Moreover, the vibration modes from the hydroxyl groups and surface adsorbed water appeared at 1635 and $3500 \mathrm{~cm}^{-1}$, respectively [22]. In addition, the organic residues from the surfactant or oleic acid present in the sample gave rise to the bands at 2930 and
$2855 \mathrm{~cm}^{-1}$, attributed to $\nu_{\mathrm{s}}\left(\mathrm{CH}_{2}\right)$ and $\nu_{\mathrm{as}}\left(\mathrm{CH}_{2}\right)$, respectively, and the band at $1470 \mathrm{~cm}^{-1}$, ascribed to $\delta\left(\mathrm{CH}_{2}\right)$ [19].

Fig. 5 illustrates the luminescence spectra. $\mathrm{YVO}_{4}$ : $\mathrm{Eu}$ has been extensively studied $[9,14,16,18,23,24]$. The excitation spectra recorded here agreed well with literature reports. A broad band emerged in the UV region due to energy transfer from vanadate ions [23]. The colloidal and microemulsion samples presented different excitation band profiles, which was a consequence of citrate complexation with the rare earth ion on the surface of the particle obtained by the colloidal methodology [18]. An interesting effect occurred in the excitation spectra after the mesoporous coating process: the relative intensity of the vanadate band increased. Quenching processes took place in the vanadate particles; that is, quenching by surface effects $\left(\mathrm{V}-\mathrm{OH}\right.$ or $\mathrm{V}_{-} \mathrm{O}^{-}$groups) or de-excitation of the vanadate species via exciton migration occurred, whereas the mesoporous silica coating suppressed the average migration [9]. Therefore, the silicate shell improved the vanadate-Eu ${ }^{3+}$ energy transfer process.

The emission spectra displayed the characteristic transition of the europium ion. In agreement with the $\mathrm{D}_{2 d}$ symmetry, the ${ }^{5} D_{0} \rightarrow{ }^{7} F_{2}$ forced electric-dipole transitions dominated the spectra. The presence of the weak band attributed to the ${ }^{5} \mathrm{D}_{0} \rightarrow{ }^{7} \mathrm{~F}_{0}$ transition at $580 \mathrm{~nm}$ evidenced distortion of the $\mathrm{D}_{2 d}$ symmetry probably due to a larger $\mathrm{Eu}-\mathrm{O}$ bond distance as compared to the $\mathrm{Y}-\mathrm{O}$ distance in the host [23]. All the other components agreed well with literature reports. The coating did not affect the vanadate structure-the spectra of the coated and non-coated samples were similar. The ${ }^{5} \mathrm{D}_{0}$ lifetime was the same for the vanadate compounds obtained by the colloidal method or by reverse microemulsion $(\tau=0.42 \mathrm{~ms})$. The coated materials had longer lifetime $(\tau=0.65 \mathrm{~ms})$, which corroborated the importance of suppressing undesirable quenching effects in non-coated samples. The $\tau_{\text {exp }}$ to $\tau_{\text {rad }}$ ratio provided the quantum efficiency $(\eta)$ of the samples [24]. The values obtained for both vanadates were similar, $\eta=0.35$ (colloidal) and $\eta=0.40$ (microemulsion). The coated particles had larger $\eta(0.62)$. Emission efficiency is related to the concentration of $\mathrm{Eu}^{3+}$ ions. According to literature data $[9,25]$, the high $\eta$ obtained for europium ion concentrations in the range of 15 to $30 \%$ agreed with the values obtained for the $\mathrm{Eu}^{3+}$ concentration (10\%) employed in this work.

Favorable optical properties of materials allow for different applications such as biological diagnostics, biolabeling, and drug delivery, for example. However, medical applications require the absence of toxicity. Petrochenko et. al. [11] have studied the 

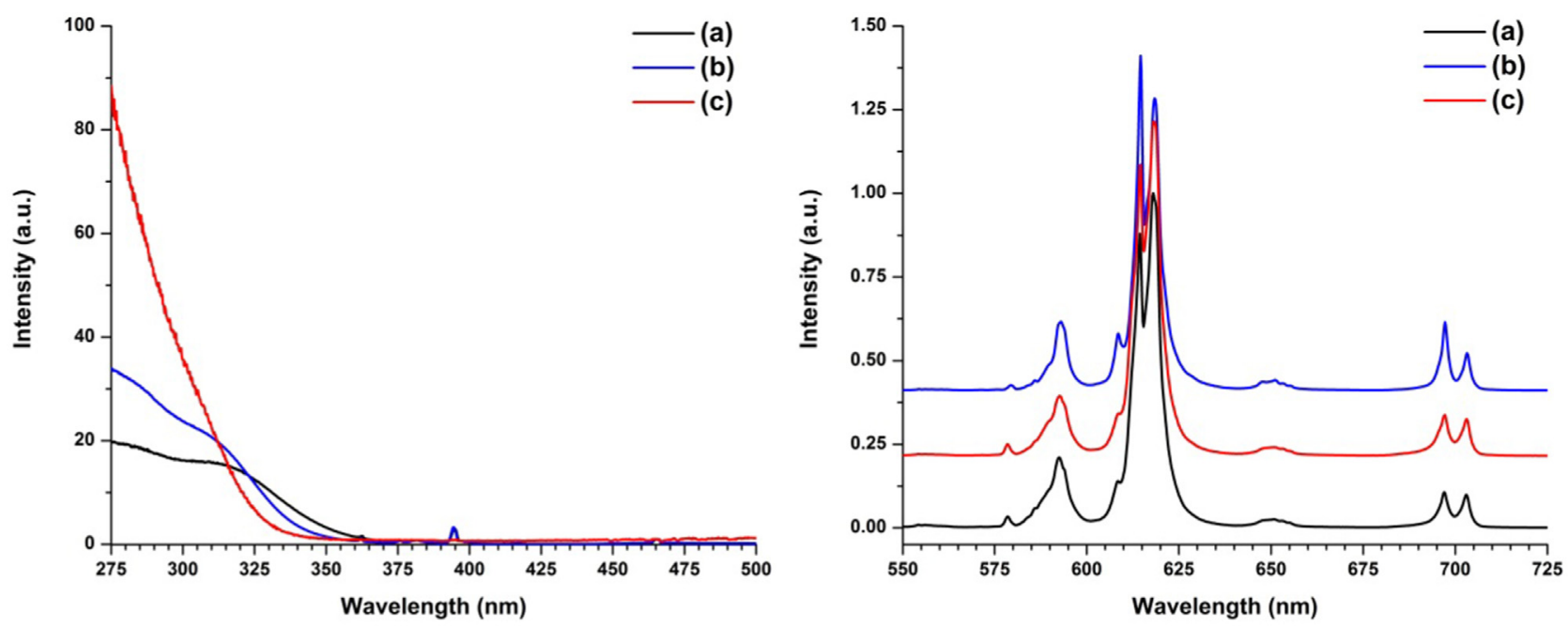

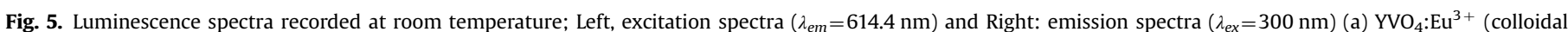
method), (b) $\mathrm{YVO}_{4}: \mathrm{Eu}^{3+}$ (reverse microemulsion synthesis), and (c) $\mathrm{YVO}_{4}: \mathrm{Eu}^{3+}$ with mesoporous silica coating (colloidal method).

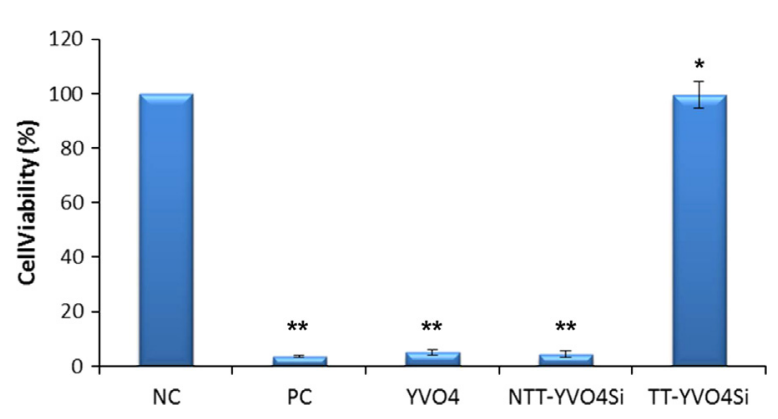

Fig. 6. Cell viability evaluated by XTT. NC represents $100 \%$ of cell viability. Columns indicate the mean value of cell viability (\%). Bars indicate the standard error. ${ }^{*}=p<0.05 ;{ }^{* *}=p<0.0001$. Dunnett's test.

toxicity of rare earth $\mathrm{YVO}_{4}$ nanoparticles. Here, we confirmed that the uncoated $\mathrm{YVO}_{4}$ :Eu particles were toxic (Fig. 6). To avoid toxicity, we applied the silica mesoporous coating to the nanoparticles.

Fig. 6 displays the cytotoxicity results (XTT cell viability assay). Cell viability is related to the absorbance. The negative control corresponded to $100 \%$ cell viability. The XTT cell viability assay is based on the cleavage of the yellow tetrazolium salt XTT by metabolically active cells, to give an orange formazan dye. This conversion only occurs in viable cells. The results obtained for the $\mathrm{NC}$ and the TT-YVO ${ }_{4} \mathrm{Si}$ eluate did not differ significantly $(p>0.05$, Dunnett), which meant that the material was not cytotoxic to CHO-K1 cells. However, the NTT-YVO 4 Si eluate decreased cell viability by $95.74 \%$, which attested to its significant cytotoxic effect. The cytotoxicity observed for the $\mathrm{NTT}^{-} \mathrm{YVO}_{4} \mathrm{Si}$ particles before the heat treatment was a consequence of the presence of surfactant in the untreated particles. Indeed, CTAB presents strong cytotoxicity [26-28].

\section{Conclusion}

The use of two different methodologies provided highly luminescent nanoparticles with efficient control of particle shape and size (15 to $70 \mathrm{~nm}$ ). Application of a mesoporous silica coating to the prepared $\mathrm{YVO}_{4}: \mathrm{Eu}^{3+}$ nanoparticles protected them from external perturbations and consequently avoided the luminescence quenching process. Application of a mesoporous structure to the nanoparticles could be useful to render these materials biocompatible and enable the creation of a multifunctional drug delivery system through incorporation of biologically active molecules. The eluate of TT-YVO ${ }_{4} \mathrm{Si}$ was not cytotoxic, but NTT$\mathrm{YVO}_{4} \mathrm{Si}$ demonstrated significant cytotoxic effect on CHO-K1 before heat treatment. Moreover, the cytotoxic effect of the CTAB surfactant used in the synthesis of the nanoparticles by reverse microemulsion was verified in this work. Finally, the mesoporous coating improved the emission efficiency and the ${ }^{5} \mathrm{D}_{0}$ lifetime.

\section{Acknowledgments}

The authors acknowledge the Brazilian agency FAPESP (Proc. 2011/21551-0) and University of São Paulo for financial support.

\section{References}

[1] A.L. Moura, V. Jerez, L.J.Q. Maia, A.S.L. Gomes, C.B. De Araujo, Sci. Rep. 5 (2015) 13816.

[2] E. Auffray, M. Korjik, T. Shalapska, S. Zazubovich, J. Lumin. 154 (2014) 381.

[3] M.A. Katkova, M.N. Bochkarev, Dalton Trans. 39 (2010) 6599.

[4] J.M.A. Caiut, S. Lechevallier, J. Dexpert-Ghys, B. Caillier, Ph Guillot, J. Lumin. 131 (2011) 628.

[5] R.R. Gonçalves, G. Carturan, M. Montagna, M. Ferrari, L. Zampedri, S. Pelli, G. Righini, S. Ribeiro, Y. Messaddeq, Opt. Mater. 25 (2004) 131.

[6] D. Ananias, F.A. Almeida Paz, D.S. Yufit, L.D. Carlos, J. Rocha, J. Am. Chem. Soc. 137 (2015) 3051.

[7] J.M.A. Caiut, S.J.L. Ribeiro, Y. Messaddeq, J. Dexpert-Ghys, M. Verelst, H. Dexpert, Nanotechnology 18 (2007) 455605.

[8] Y. Zhou, J. Lin, M. Yu, S. Wang, J. Alloys Compd. 375 (2004) 93.

[9] A. Huignard, V. Buissette, A.C. Franville, T. Gacoin, J. Boilot, J. Phys. Chem. B 107 (2003) 6754.

[10] D. Giaume, V. Buissette, K. Lahlil, T. Gacoin, J.P. Boilot, D. Casanova, E. Beaurepaire, M.P. Sauviat, A. Alexandrou, Prog. Solid State Chem. 33 (2005) 99.

[11] P.E. Petrochenko, Q. Zhang, H. Wang, T. Sun, B. Wildt, M.W. Betz, P.L. Goering, R.J. Narayan, Int. J. Appl. Ceram. Technol. 9 (2012) 881.

[12] S. Gai, P. Yang, D. Wang, C. Li, N. Niu, F. He, M. Zhang, J. Lin, RSC Adv. 2 (2012) 3281.

[13] J. Kim, J.E. Lee, J. Lee, J.H. Yu, B.C. Kim, K. An, Y. Hwang, C.H. Shin, J.G. Park, J. Kim, T. Hyeon, J. Am. Chem. Soc. 128 (2006) 688.

[14] Y.S. Cho, Y.D. Huh, Bull. Korean Chem. Soc. 32 (2011) 335.

[15] G. Pan, H. Song, Q. Dai, R. Qin, X. Bai, B. Dong, L. Fan, F. Wang, J. Appl. Phys. 104 (2008) 084910.

[16] A. Huignard, T. Gacoin, P.J. Boilot, Chem. Mater. 12 (2000) 1090.

[17] G. Cao, Nanostructures \& Nanomaterials: Synthesis, Properties \& Applications, first ed., Imperial College Press, London, 2004.

[18] A. Huignard, V. Buissette, G. Laurent, T. Gacoin, J.P. Boilot, Chem. Mater. 14 (2002) 2264.

[19] M. Liong, J. Lu, M. Kovochich, T. Xia, S.G. Ruehm, A.E. Nel, F. Tamanoi, J.I. Zink, ACS Nano 2 (2008) 889.

[20] L. Wei, Z. Ming, Z. Jinli, H. Yongcai, Front. Chem. 4 (2006) 438. 
[21] S. Gai, P. Yang, P. Ma, L. Wang, C. Li, M. Zhang, L. Jun, Dalton Trans. 41 (2012) 4511.

[22] L.A. Rocha, J.C. Freiria, J.M.A. Caiut, S.J.L. Ribeiro, Y. Messaddeq, M. Verelst, J. Dexpert-Ghys, Nanotechnology 26 (2015) 335604.

[23] C. Hsu, R.C. Powell, J. Lumin. 10 (1975) 273.

[24] A.P. Duarte, M. Gressier, M.J. Menu, J. Dexpert-Ghys, J.M.A. Caiut, S.J.L. Ribeiro, J. Phys. Chem. C 116 (2012) 505.

[25] R.C.J. Ropp, Electrochem. Soc. Solid State Sci. 115 (1968) 940.
[26] T. Niidome, M. Yamagata, Y. Okamoto, Y. Akiyama, H. Takahashi, T. Kawano, Y. Katayama, Y. Niidome, J. Control. Release. 114 (2006) 343.

[27] E. Yasun, C. Li, I. Barut, D. Janvier, L. Qiu, C. Cui, W. Tan, Nanoscale 7 (2015) 10240.

[28] J. Guo, M.J. Armstrong, C.M. O'Driscoll, J.D. Holmes, K. Rahme, RSC Adv. 5 (2015) 17862. 